\title{
Caracterização e tratabilidade biológica dos efluentes líquidos gerados em cabines de pintura de uma indústria moveleira
}

\section{Characterization and treatability of wastewater from a dying hood of a furniture industry}

\author{
Anselmo R. Lage Santos \\ Químico pela Universidade Federal de Viçosa (UFV). Mestre em Engenharia Ambiental pela Universidade Federal de Ouro Preto (UFOP)
}

\author{
Sérgio F. Aquino \\ Professor do Departamento de Química da UFOP \\ Cornélio F. Carvalho \\ Professor do Departamento de Química da UFOP
}

Laura Aparecida Vieira

Aluna de Iniciação Científica da UFOP

Erik Sartori Jeunon Gontijo

Aluno de Iniciação Científica da UFOP

\section{Resumo}

O objetivo deste trabalho foi caracterizar os efluentes gerados em cabines de pintura de uma indústria moveleira e avaliar a eficiência de sistemas biológicos (anaeróbio e aeróbio) para o seu tratamento. O efluente industrial apresentou elevado teor de matéria orgânica (DQO total de 634 a 2.790 mg. $\mathrm{L}^{-1}$; DBO 5 total de 360 a 972 mg..$^{-1}$ ) e baixos teores de macronutrientes (NTK de 1,9 mg. L $^{-1}$ e $P_{\text {total }}$ de $0,5 \mathrm{mg} . L^{-}$) e metais tóxicos. Os ensaios de tratabilidade em reator UASB $\left(\sim 25^{\circ} \mathrm{C}\right.$ e tempo de detenção hidráulica - TDH $=10$ horas), indicaram uma eficiência máxima de remoção de matéria orgânica de $90 \%$ na composição volumétrica 70:30 (efluente industrial:esgoto sanitário). A alimentação do reator UASB só com efluente industrial resultou em acúmulo de ácidos graxos voláteis e inibição microbiana, mas o uso de pós-tratamento aeróbio (TDH = 96h) garantiu elevada eficiência global ( 88\%) de remoção de matéria orgânica.

Palavras-chave: água residuária da indústria moveleira; tratamento biológico; biodegradabilidade; reator anaeróbio de fluxo ascendente; tratamento anaeróbio pós-tratamento aeróbio; sistema combinado.

\begin{abstract}
The main objective of this work was to characterize the wastewater from the dying hood of a woven furniture industry, and to assess the efficiency of biological processes (anaerobic and aerobic) for its treatment. The physical-chemical characterization of the industrial wastewater showed a high organic matter content (total COD from 634 to 2,790 mg. $\mathrm{L}^{-1}$; total $\mathrm{BOD}_{5}$ from 360 to $972 \mathrm{mg} \cdot \mathrm{L}^{-1}$ ), low content of macronutrients (NTK of $1.9 \mathrm{mg} \cdot \mathrm{L}^{-1}$ and P of $0.5 \mathrm{mg} . \mathrm{L}^{-1}$ ) and toxic metals. The anaerobic degradation tests in a bench-scale UASB reactor $\left(25^{\circ} \mathrm{C}\right.$ and hydraulic retention time $-\mathrm{HRT}=10$ hours $)$ showed that a maximum removal efficiency of $90 \%$ was obtained when the reactor was fed with $30 \%$ raw sewage and $70 \%$ industrial wastewater. The feeding of UASB reactor with only industrial wastewater resulted in volatile fatty acids accumulation and microbial inhibition; however, the use of aerobic post-treatment (HRT $=96$ hours) granted a high $(\sim 88 \%)$ organic matter removal efficiency.
\end{abstract}

Keywords: wood furniture wastewater; biological treatment; biodegradability; UASB reactor; anaerobic treatment; aerobic post-treatment; combined systems. 


\section{Introdução}

O setor moveleiro tem apresentado um grande crescimento no Brasil nas últimas décadas. De acordo com a Associação Brasileira de Indústrias Moveleiras (ABIMÓVEL, 2001), em 2003 existiam cerca de 16.112 empresas moveleiras, gerando cerca de 190 mil empregos, com a produção concentrando-se em móveis residenciais (60\%), escritório (27\%) e institucionais, escolares, médico-hospitalares, restaurantes, hotéis e similares (15\%). Os principais polos moveleiros encontram-se nas regiões Sul e Sudeste, mais especificamente nas cidades de Bento Gonçalves, Rio Grande do Sul, São Bento do Sul, Santa Catarina, Arapongas, Paraná, Mirassol e Votuporanga, São Paulo, Ubá, Minas Gerais e Linhares, Espírito Santo.

A indústria moveleira caracteriza-se pelo uso integrado de materiais de natureza distinta, tais como madeira maciça e painéis derivados (com e sem acabamento); lâminas naturais de madeiras; laminados plásticos, compostos de diferentes materiais e resinas; metais (aço, alumínio e latão); produtos químicos (colas, tintas e vernizes); vidros e cristais; tecidos e couros (naturais e sintéticos); pedras ornamentais (mármores e granitos), entre outros. Dessa forma, a atividade de produção de móveis produz resíduos sólidos, líquidos e gasosos de características diversas, altamente dependentes do produto elaborado e comercializado.

$\mathrm{Na}$ fabricação de móveis, os resíduos sólidos são gerados na primeira etapa do processamento, durante as atividades de corte, perfuração e polimento da madeira. Tais resíduos são normalmente empregados na própria região, podendo ser utilizados como adubo após processo de compostagem ou como combustível para produção de energia. Contudo, em muitos casos, tais resíduos têm sido desperdiçados, sendo que muitas empresas promovem a queima do material para redução de volume sem aproveitamento energético dos mesmos (SCHENEIDER et al., 2003)

Por sua vez, os efluentes líquidos e gasosos são normalmente gerados nas etapas de acabamento, principalmente durante a atividade de pintura. A pintura de móveis é normalmente feita em cabine circundada por cortinas de água, de forma a controlar a emissão para a atmosfera de vapores de produtos químicos constituintes das tintas, vernizes e solventes utilizados. A geração de águas residuárias decorre diretamente da atividade de controle da poluição atmosférica e da limpeza de recipientes, embalagens e utensílios utilizados durante a pintura. Dessa forma as águas residuárias da cabine de pintura podem conter compostos orgânicos - como cetonas, ésteres, hidrocarbonetos aromáticos (principalmente xileno e tolueno) e resinas - e inorgânicos, como aqueles utilizados em pigmentos sintéticos. Tais substâncias contribuem para a elevada carga orgânica e potencialmente tóxica das águas residuárias geradas.

Várias empresas do setor moveleiro tratam as águas residuárias geradas, muito embora também seja prática comum lançar tais efluentes diretamente nos corpos d'água sem qualquer tratamento prévio. O tratamento normalmente utilizado nas indústrias moveleiras emprega a coagulação/floculação com cal ou coagulantes convencionais, e não tem se mostrado eficiente na redução da sua carga tóxica (FERREIRA, 2003).

Uma opção para o tratamento de águas residuárias industriais que contêm compostos orgânicos biodegradáveis não tóxicos (por exemplo, cetonas, ésteres e alcoóis) seria a utilização de processos biológicos, principalmente os que empregam sistemas que combinam reatores anaeróbios de manta de lodo (UASB) com o pós-tratamento aeróbio (por exemplo, lodos ativados e lagoas aeradas). Dessa forma, tendo em vista a importância da indústria moveleira para a economia e o impacto ambiental causado por tal atividade econômica, o presente trabalho teve como objetivo caracterizar os efluentes gerados na cabine de pintura de uma indústria moveleira, bem como avaliar sua tratabilidade anaeróbia e aeróbia.

\section{Materiais e métodos}

\section{Amostragem}

As amostras de água residuária industrial foram coletadas diretamente das cabines de pintura de uma indústria moveleira localizada na cidade de Belo Horizonte, Minas Gerais. O efluente ficava armazenado no tanque da cabine de pintura por aproximadamente sete dias, em constante recirculação, sendo posteriormente descartado. A coleta de amostra era feita quinzenalmente, em dia anterior ao descarte e esvaziamento do tanque de armazenamento. As amostras eram coletadas diretamente do tanque de armazenamento, sendo o efluente estocado sob refrigeração $\left(a 4^{\circ} \mathrm{C}\right)$ até a sua caracterização e utilização nos experimentos de tratabilidade. Ao todo, foram feitas 10 coletas distintas de efluentes durante os 150 dias de alimentação contínua do reator anaeróbio de bancada.

\section{Caracterização físico-química das amostras}

As amostras de água residuária industrial foram caracterizadas utilizando-se os seguintes parâmetros físicos e químicos: temperatura, condutividade, alcalinidade, série de sólidos, série de nitrogênio, fósforo total, demanda química de oxigênio (DQO), demanda bioquímica de oxigênio (DBO), óleos e graxas e metais totais (Al, Ba, $\mathrm{Fe}, \mathrm{Mn}, \mathrm{Sr}, \mathrm{Cr}, \mathrm{Cu}, \mathrm{Zn}, \mathrm{Ca}, \mathrm{Mg}, \mathrm{Na}, \mathrm{K}, \mathrm{Be}, \mathrm{Cd}, \mathrm{Cr}$ e Ni). Todas as análises foram realizadas de acordo com o Standard Methods for the Examination of Water and Wastewater (APHA, AWWA, WEF, 1998), sendo os metais analisados por espectrofotometria de emissão atômica com fonte de plasma (ICP-OES) conforme o método 3120B.

Análises de ácidos graxos voláteis (AGV) também foram feitas em algumas amostras do efluente anaeróbio. Para análise de tais intermediários da digestão anaeróbia, foi utilizada uma coluna de troca iônica Aminex HPX-874 (Bio-Rad), conectada a um cromatógrafo 
de fase líquida (Hewlett Packard), série 1050, com detector UV-Vis (ultravioleta - visível) no comprimento de onda $(\lambda)$ de $210 \mathrm{~nm}$. A fase móvel $\left(\mathrm{H}_{2} \mathrm{SO}_{4} 0,01 \mathrm{M}\right)$ foi mantida em regime isocrático $(0,6$ $\mathrm{mL} \cdot \mathrm{min}^{-1}$ ), a coluna foi mantida à temperatura de $55^{\circ} \mathrm{C}$ e o volume de injeção empregado foi o de $10 \mu \mathrm{L}$. A quantificação dos AGV foi feita por padronização externa, com curva de calibração na faixa de 12,5 a $400 \mathrm{mg} \cdot \mathrm{L}^{-1}$, tendo sido analisados os ácidos fórmico, acético, propiônico, isobutírico, butírico, isovalérico e valérico, conforme detalhes apresentados em Mesquita (2009), que fez a devida validação do método de análise.

\section{Ensaio de tratabilidade anaeróbia}

Os ensaios de tratabilidade anaeróbia foram feitos empregando-se um reator anaeróbio de fluxo ascendente e manta de lodo (UASB), em escala de bancada (Figura 1), alimentado continuamente. O reator de bancada foi inoculado com lodo anaeróbio ( $30 \mathrm{~g}$ SSV/L) proveniente de reator UASB operado em escala de bancada e alimentado com esgoto sanitário no Centro de Pesquisa e Treinamento em Saneamento (CePTS) da Universidade Federal de Minas Gerais (UFMG) e Companhia de Saneamento de Minas Gerais (COPASA). Para a partida do reator UASB de bancada, a carga orgânica específica foi de, aproximadamente, 0,15 $\mathrm{kg}$ DQO $/ \mathrm{kg}$ SSV.dia, valor dentro da faixa recomendada $(0,05$ a $0,5 \mathrm{~kg}$ DQO/kg STV.dia) por Chernicharo (2007).

O volume útil do reator era de $8 \mathrm{~L}$, com 2 L na câmara de decantação $(\mathrm{d}=75 \mathrm{~mm})$ e $6 \mathrm{~L}$ na câmara de digestão $(\mathrm{d}=50 \mathrm{~mm})$. A câmara de decantação continha um funil invertido atuando como separador trifásico e permitindo a coleta do biogás, que não foi caracterizado em função de dificuldades técnicas para a quantificação de metano e da baixa produção de biogás observada. Na câmara de digestão, foram colocadas 4 torneiras, a cada $15 \mathrm{~cm}$, para a coleta de amostras de lodo anaeróbio, e a velocidade ascensional foi calculada em $0,17 \mathrm{~m} /$ hora. Tal valor é menor do que a faixa recomendada $(0,5$ a $0,7 \mathrm{~m} /$ hora) por Chernicharo (2007), e isso resultou na ausência de arraste de biomassa para o efluente. De fato, ao longo de toda a operação do UASB de bancada, o lodo acumulado atingiu no máximo a altura correspondente à terceira torneira.

O sistema de alimentação consistia em um recipiente de plástico de $20 \mathrm{~L}$, que era abastecido diariamente com o efluente mantido em geladeira a $4^{\circ} \mathrm{C}$. Tal recipiente de alimentação era mantido à temperatura ambiente sobre um agitador magnético para evitar eventual sedimentação de sólidos. Do reservatório de alimentação, a água residuária era introduzida no reator por uma bomba peristáltica modelo Dosa Mini 400 (HD - Hidraulis Ltda), na vazão estipulada para manutenção dos tempos de detenção hidráulica (TDH) impostos. A faixa de TDH estudada foi de 20 horas (inicial) a 10 horas (final), o que implicou em vazões volumétricas variando de 0,40 a 0,80 L.h.-1.

Iniciou-se o tratamento mantendo-se o TDH em 20 horas e alimentando-se o reator apenas com o esgoto produzido no campus da
Universidade Federal de Ouro Preto (UFOP), que foi caracterizado como tipicamente doméstico, conforme Bertolino (2007). O TDH foi, então, gradativamente reduzido até 10 horas, durante um período de 35 dias antes de o reator ser alimentado com água residuária industrial. Passada essa primeira etapa, o TDH foi mantido em 10 horas e foram introduzidos volumes crescentes de água residuária da indústria moveleira, conforme a Tabela 1.

Por todo o período de operação do reator, não houve descarte de lodo, a não ser durante as coletas de amostras para caracterização físico-química e análise da eficiência do tratamento, que foi obtida em todas as fases do tratamento considerando-se a remoção de DQO total afluente e DQO total efluente.

\section{Ensaio de tratabilidade aeróbia}

O ensaio de tratabilidade aeróbia foi feito empregando-se um sistema de alimentação semicontínua, que consistia em coletar um volume específico do efluente anaeróbio e introduzir em um reator aeróbio de bancada previamente inoculado com lodo aeróbio, coletado em um sistema de lodos ativados operado em escala real e alimentado com esgoto sanitário (Estação de Tratamento de Efluentes Arrudas,

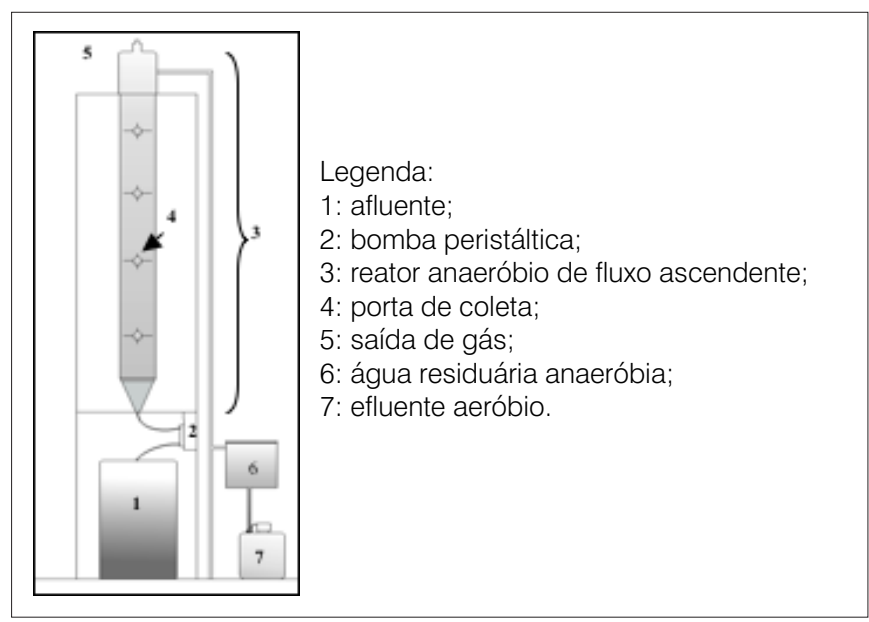

Figura 1 - Representação esquemática do reator anaeróbio de fluxo ascendente

Tabela 1 - Variação das proporções volumétricas de água residuária industrial e esgoto sanitário ao longo das fases de operação do reator anaeróbio de fluxo ascendente

\begin{tabular}{lccc} 
Fase & $\begin{array}{c}\text { \% água residuária } \\
\text { industrial }\end{array}$ & \% esgoto sanitário & Duração (dias) \\
I & 0 & 100 & 35 \\
II & 5 & 95 & 20 \\
III & 10 & 90 & 21 \\
IV & 20 & 80 & 10 \\
V & 30 & 70 & 14 \\
VI & 50 & 50 & 11 \\
VII & 70 & 30 & 10 \\
VIII & 90 & 10 & 12 \\
IX & 100 & 0 & 25 \\
\hline
\end{tabular}


Belo Horizonte, Minas Gerais). O reator aeróbio de bancada $\left(\mathrm{V}_{\text {util }}=4\right.$ L) era mantido à temperatura ambiente e sob aeração contínua por meio de aeradores de aquário e pedras porosas.

Decorridas 48 horas de operação, o aerador era desligado e, após o lodo sedimentar, eram então retirados 2 L do sobrenadante (efluente tratado) para caracterização físico-química. Um volume igual de efluente anaeróbio era, então, introduzido novamente no reator aeróbio antes de reiniciar a aeração e a operação pelas 48 horas seguintes. Dessa forma, o reator aeróbio foi operado com TDH teórico de 4 dias, por um período de 10 dias. Cabe ressaltar que a eventual evaporação de água era reposta com água destilada, mantendo-se, assim, o volume útil em 4 L. Da mesma forma que no reator anaeróbio, durante todo o período de operação não houve descarte de lodo aeróbio.

\section{Resultados e discussão}

\section{Caracterização da água residuária industrial}

A Tabela 2 apresenta a caracterização da água residuária gerada nas cabines de pintura de uma indústria moveleira conforme os parâmetros físicos e químicos, ao passo que a Tabela 3 apresenta os valores de concentração de metais encontrados em tal efluente.

Em relação aos dados apresentados na Tabela 2, percebe-se que, embora os valores de DQO sejam elevados, a relação DQO/DBO é menor do que 2,5 , indicando que tal despejo pode potencialmente ser tratado por processos biológicos (VON SPERLING, 1996).

Tabela 2 - Caracterização da água residuária da cabine de pintura de indústria moveleira. Valores médios de cinco coletas realizadas ao longo do monitoramento do reator anaeróbio de fluxo ascendente

\begin{tabular}{|c|c|c|c|c|c|c|}
\hline Parâmetros & Mínimo & Máximo & $\begin{array}{l}\text { Média } \\
{ }^{*} n=5\end{array}$ & Desvio padrão & Coeficiente de variação & Padrão COPAM** \\
\hline DQO total $\left(\mathrm{mg} \cdot \mathrm{L}^{-1}\right)$ & 634,0 & 2790,0 & 1725,0 & 375,0 & 0,22 & $\leq 180,0^{* \star *}$ \\
\hline DQO filtrada $\left(\mathrm{mg} \cdot \mathrm{L}^{-1}\right)$ & 495,0 & 934,0 & 770,0 & 110,0 & 0,14 & - \\
\hline SST (mg. $\left.\mathrm{L}^{-1}\right)$ & 538,0 & 1058,0 & 736,0 & 130,0 & 0,18 & $\leq 100,0$ \\
\hline SSV (mg. $\left.L^{-1}\right)$ & 428,0 & 876,0 & 639,0 & 112,0 & 0,17 & - \\
\hline $\mathrm{DBO}\left(\mathrm{mg} \cdot \mathrm{L}^{-1}\right)$ & 364,0 & 972,0 & 745,0 & 150,0 & 0,20 & $\leq 60,0$ \\
\hline Condutividade $\left(\mu \mathrm{s} . \mathrm{cm}^{-1}\right)$ & 172,0 & 972,0 & 482,0 & 200,0 & 0,41 & - \\
\hline $\mathrm{P}$ - total $\left(\mathrm{mg} \cdot \mathrm{L}^{-1}\right)$ & 0,305 & 0,702 & 0,507 & 0,099 & 0,20 & 0,025 \\
\hline $\mathrm{N}-\mathrm{NKT}\left(\mathrm{mg} \cdot \mathrm{L}^{-1}\right)$ & 0,0 & 4,8 & 1,9 & 1,2 & 0,63 & - \\
\hline Óleos e graxas $\left(m g \cdot \mathrm{L}^{-1}\right)$ & 39,5 & 45,7 & 42,6 & 1,55 & 0,036 & Ausentes \\
\hline $\mathrm{pH}$ & 5,42 & 7,29 & 6,35 & 0,467 & 0,07 & 6,0 a 9,0 \\
\hline
\end{tabular}

*n = número de análises realizadas para obtenção dos valores médios.

** Padrão de lançamento de efluentes, de acordo com o disposto no artigo 29 da Deliberação Normativa Conjunta COPAM/CERH-MG no 1, de 5 de maio de 2008 (COPAM; CERH-MG, 2008 ).

*** Ou tratamento com eficiência de redução de DQO em, no mínimo, $70 \%$ média anual igual ou superior a $75 \%$ para os sistemas, exceto sistemas de esgotos sanitários e de percolados de aterros sanitários municipais, efluentes de indústria têxtil ou efluentes de fabricação de celulose Kraft branqueada.

Tabela 3 - Concentrações dos metais na água residuária da indústria moveleira

\begin{tabular}{|c|c|c|c|c|c|c|c|}
\hline Metal (mg. $\mathrm{L}^{-1}$ ) & LQ & Média * $n=3$ & Mínimo & Máximo & Desvio Padrão & Coeficiente de Variação & Limite COPAM/CERH ** \\
\hline $\mathrm{Al}$ & 0,249 & $<\mathrm{LQ}$ & - & - & - & - & - \\
\hline $\mathrm{Ba}$ & 0,001 & 0,1566 & 0,1478 & 0,1653 & 0,012 & 0,079 & 5,0 \\
\hline $\mathrm{Be}$ & 0,001 & $<\mathrm{LQ}$ & - & - & - & - & - \\
\hline $\mathrm{Ca}$ & 0,343 & 41,24 & 28,68 & 53,80 & 17,76 & 0,43 & - \\
\hline $\mathrm{Cd}$ & 0,006 & $<\mathrm{LQ}$ & - & - & - & - & 0,1 \\
\hline Co & 0,007 & $<\mathrm{LQ}$ & - & - & - & - & - \\
\hline $\mathrm{Cr}$ & 0,011 & 0,0242 & 0,0111 & 0,0372 & 0,0185 & 0,763 & 1,0 \\
\hline $\mathrm{Cu}$ & 0,006 & - & $<\mathrm{LQ}$ & 0,0076 & - & - & 1,0 \\
\hline $\mathrm{Fe}$ & 0,660 & 5,525 & 4,069 & 6,980 & 2,058 & 0,3726 & 15,0 \\
\hline $\mathrm{K}$ & 0,062 & 1,341 & 1,336 & 1,345 & 0,006 & 0,0045 & - \\
\hline $\mathrm{Li}$ & 0,003 & 0,0217 & 0,0113 & 0,0321 & 0,023 & 1,072 & - \\
\hline $\mathrm{Mg}$ & 0,013 & 4,571 & 4,457 & 4,685 & 0,161 & 0,0352 & - \\
\hline $\mathrm{Mn}$ & 0,010 & $<\mathrm{LQ}$ & - & - & - & - & 1,0 \\
\hline Mo & 0,033 & $<\mathrm{LQ}$ & - & - & - & - & - \\
\hline $\mathrm{Na}$ & 0,458 & 4,972 & 3,333 & 6,610 & 2,317 & 0,466 & - \\
\hline $\mathrm{Ni}$ & 0,016 & $<\mathrm{LQ}$ & - & - & - & - & 1,0 \\
\hline $\mathrm{Pb}$ & 0,065 & $<\mathrm{LQ}$ & - & - & - & - & 0,1 \\
\hline $\mathrm{Sr}$ & 0,0003 & 0,1101 & 0,0889 & 0,1312 & 0,0292 & 0,265 & - \\
\hline $\mathrm{Ti}$ & 0,006 & 0,0242 & 0,0145 & 0,0338 & 0,0136 & 0,564 & - \\
\hline V & 0,099 & $<\mathrm{LQ}$ & - & - & - & - & - \\
\hline $\mathrm{Zn}$ & 0,027 & 0,7747 & 0,4414 & 1,1080 & 0,4713 & 0,608 & 5,0 \\
\hline
\end{tabular}

LQ: limite de quantificação; *n: número de análises realizadas para obtenção dos valores médios; **limites individuais de lançamento de efluente, atendendo o disposto no artigo 29 da Deliberação Normativa Conjunta COPAM/CERH-MG no 1, de 5 de maio de 2008 (COPAM; CERH-MG, 2008). 
Verifica-se que a especiação da DQO indica, em termos médios, que existe uma igualdade entre o material particulado e dissolvido. Do material particulado, a maior parte é orgânica, conforme indicado pela elevada relação SSV/SST (sólidos suspensos voláteis/ sólidos suspensos totais). A alta carga orgânica da água residuária industrial é devido, principalmente, à presença de tintas e solventes utilizados nas atividades de acabamento final dos móveis nas cabines de pintura.

O baixo valor de condutividade do efluente reflete a baixa concentração de sólidos inorgânicos dissolvidos, indicando que o conteúdo de compostos inorgânicos (por exemplo, sulfatos, metais e nitratos) é baixo. Isso decorre da pouca ou não utilização de ácidos inorgânicos, sais e bases nas cabines de pintura. O baixo teor de metais dissolvidos é corroborado pelos dados da Tabela 3, a despeito dos pigmentos utilizados na atividade de pintura.

A relação DQO:N:P da água residuária industrial foi calculada em 350:0,39:0,10, sugerindo que a água residuária é deficiente em fósforo e, principalmente, em nitrogênio, considerando-se a relação supostamente ideal para o tratamento anaeróbio reportada em 350:5:1 (VON SPERLING, 1996). Conforme será visto posteriormente, uma estratégia adotada para o tratamento da referida água residuária industrial é a sua composição com os esgotos sanitários produzidos nas indústrias moveleiras (sanitários, cantinas, banhos), o que garante a complementação de nitrogênio e fósforo necessários para o tratamento anaeróbio e aeróbio.

$\mathrm{Na}$ Tabela 3, pode-se observar que os metais $\mathrm{Ca}, \mathrm{Mg}, \mathrm{Na}$ e $\mathrm{Fe}$ estão em maiores concentrações na água residuária industrial. O Ca e Mg são normalmente presentes na água captada pela empresa e originam-se da dissolução de rochas calcárias, ao passo que o Fe pode ser resultado da corrosão de tubulações utilizadas no transporte e circulação de água na cabine de pintura. De qualquer forma, não foram encontradas concentrações de metais acima do limite máximo permitido para o lançamento de efluentes, de acordo com a Deliberação Normativa no 1 do COPAM/CERH-MG (2008). Os metais $\mathrm{Na}, \mathrm{Ca}, \mathrm{K}$ e $\mathrm{Mg}$ que foram encontrados com concentrações acima de 1,0 mg/L não possuem valores limites para lançamento de acordo com a Deliberação Normativa COPAM/CERH 01/2008, sendo que os metais $\mathrm{Al}, \mathrm{Be}, \mathrm{Co}, \mathrm{Mn}, \mathrm{Mo}, \mathrm{Ni}, \mathrm{Pb}$ e $\mathrm{V}$ não foram detectados nas amostras analisadas. Além disso, as concentrações médias de metais da água residuária industrial são inferiores aos valores considerados tóxicos para micro-organismos anaeróbios, conforme reportado por Speece (1996).

\section{Ensaio de tratabilidade anaeróbia}

A Figura 2 apresenta os resultados da DQO (total e filtrada) afluente e efluente ao reator anaeróbio de fluxo ascendente.
Verifica-se que nas quatro primeiras fases (primeiros 90 dias de operação), a DQO total afluente variou, em termos de mediana, de 900 a 1.200 mg. $\mathrm{L}^{-1}$, sendo que, para a DQO filtrada, a mediana ficou em torno de $500 \mathrm{mg}$. $\mathrm{L}^{-1}$. Tais resultados indicam que cerca de metade dos compostos causadores de DQO presentes no efluente industrial estão na forma particulada ( $x>1,2 \mu \mathrm{m})$. A mediana da DQO total efluente do reator no mesmo período variou de 300 a $600 \mathrm{mg} . \mathrm{L}^{-1}$, sendo que, para a DQO filtrada efluente, a mediana variou de 250 a $500 \mathrm{mg} . \mathrm{L}^{-1}$, indicando que a maior parte da DQO do efluente anaeróbio era devido a compostos dissolvidos. Isso era esperado, tendo-se em vista que o teor de sólidos no efluente do reator anaeróbio era baixo em função da baixa velocidade ascensional na câmara de digestão e no decantador. Conforme pode ser observado na Figura 3, a despeito da elevada variabilidade e quantidade de sólidos afluentes, o reator anaeróbio de fluxo ascendente foi capaz de consistentemente produzir um efluente com baixo teor de sólidos.

Pode-se observar que, a partir do $3^{\circ}$ mês de operação, a carga orgânica média aplicada foi aumentada de 2,7 para 5,3 kgDQO $\mathrm{m}^{-3} \cdot \mathrm{d}^{-1}$, devido ao aumento no valor médio da DQO total da água residuária industrial. Tal aumento no valor de DQO total foi, possivelmente, devido ao maior tempo de permanência da água nas cabines de pintura, ou seja, o maior tempo de recirculação da água resultou no aumento da concentração de compostos orgânicos voláteis absorvidos (por exemplo, cetonas, ésteres etc.). De qualquer forma, as Figuras 2 e 3 mostram que a duplicação da carga orgânica pouco afetou o desempenho do reator anaeróbio de fluxo ascendente, que seguiu produzindo água residuária com DQO total e filtrada na faixa de 150 a $800 \mathrm{mg} . \mathrm{L}^{-1}$ e continha sólidos inferiores ao limite de lançamento (100 mg. $\mathrm{L}^{-1}$ ) estabelecido pela legislação ambiental do Estado de Minas Gerais.

A Figura 4 mostra que houve pouca variação da temperatura no decorrer do processo, não sendo, portanto, responsável pela maior ou menor eficiência do reator em determinada fase. Em relação ao $\mathrm{pH}$, observa-se que nas cinco primeiras fases operacionais o seu valor médio no efluente permaneceu na faixa de 6,8 a 7,2. A partir do momento em que o reator começou a ser alimentado com afluente constituído de $70 \%$ de água residuária industrial, percebeu-se maior tendência à redução do $\mathrm{pH}$, provavelmente devido ao maior acúmulo de AGV intermediários da digestão anaeróbia.

O acúmulo de AGV em sistemas anaeróbios pode ocorrer devido à deficiência nutricional ou presença de compostos tóxicos no efluente industrial. Da Tabela 1 percebe-se que a relação DQO:N:P para o efluente industrial é, em média, de 350:0,38:0,10 ou 1000:1,10:0,58; o que indica que há deficiência de P e N para o tratamento anaeróbio, uma vez que as quantidades mínimas sugeridas por Chernicharo (2007) são de 350:5:1 para biomassa anaeróbia de baixo crescimento ( $\mathrm{Y} \sim 0,05$ gSSV/gDQO) ou de 1000:5:1 se a biomassa for de alto crescimento ( $\sim$ 0,15 gSSV/gDQO). Utilizando 

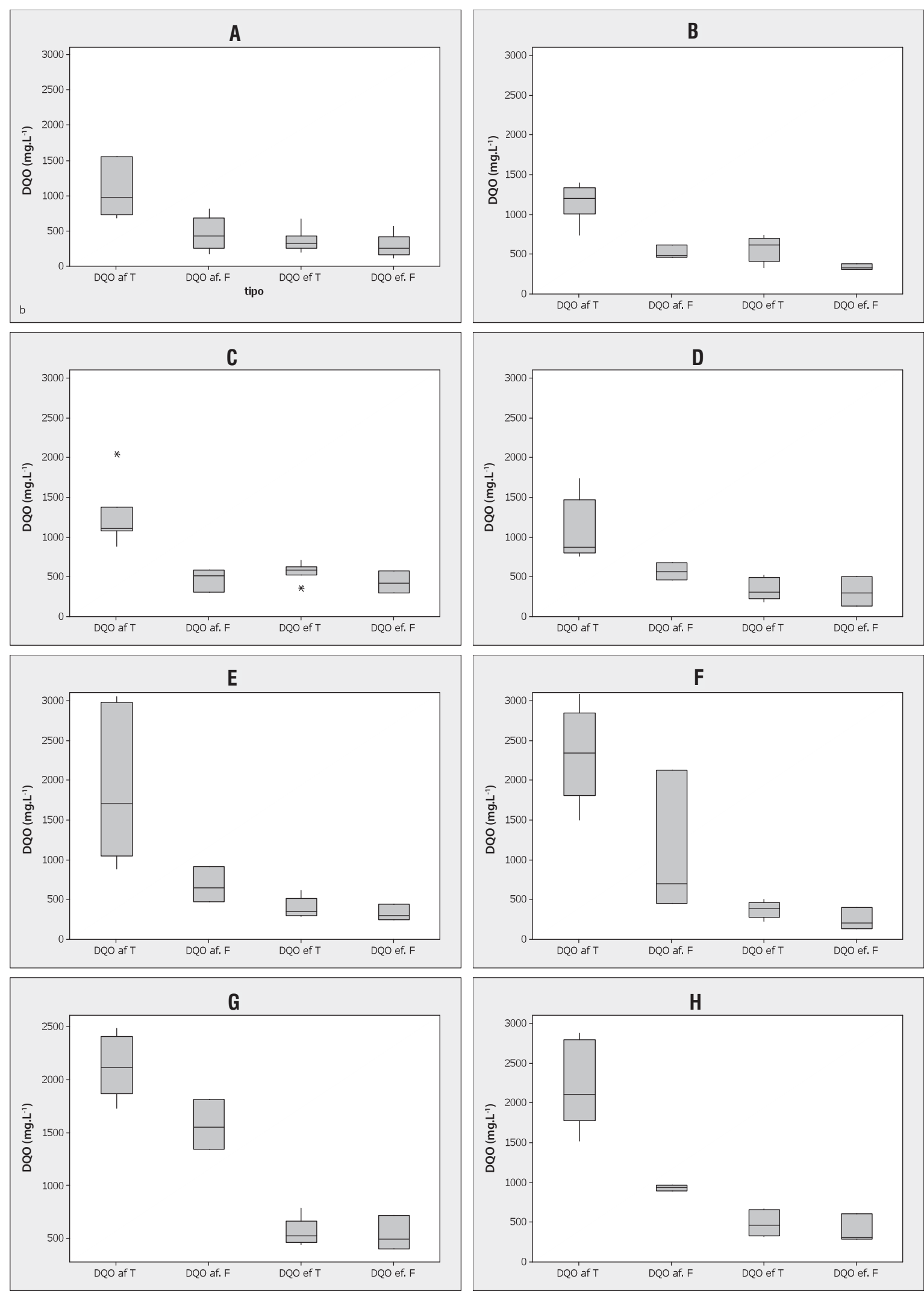

DQO af T: DQO afluente total;

$\mathrm{DQO}$ af $\mathrm{F}: \mathrm{DQO}$ afluente filtrada;

DQO ef T: DQO efluente total;

DQO ef F: DQO efluente filtrada.

Figura 2 - Variação da DQ0 total e filtrada afluente e efluente ao reator anaeróbio de fluxo ascendente durante as fases operacionais estudadas. (A) fase I; (B) fase II; (C) fase III; (D) fase V; (E) fase VI; (F) fase VII; (G) fase VIII; (H) fase IX. Duração da fase conforme Tabela 1 
dados apresentados em Bertolino (2008), a composição de 70\% de efluente industrial com 30\% de esgoto do campus da UFOP resultaria em relação DQO:N:P de 350:4:0,5 ou 1000:12:1,4. Dessa forma, percebe-se que a composição volumétrica 70:30 (efluente industrial:esgoto tipicamente sanitário) fornece, no limite, condições nutricionais para biomassa anaeróbia de elevado crescimento.

A Figura 5 mostra que a eficiência de remoção de DQO total variou de 50 a $82 \%$, atingindo o valor máximo na fase VII, quando a água residuária industrial representava 70\% do afluente alimentado no reator anaeróbio de fluxo ascendente. O fato de maiores eficiências de remoção não terem sido observadas em composições com maior proporção de esgoto sanitário (por exemplo, 50:50) pode estar relacionado ao menor tempo de aclimatação da biomassa. Por outro lado, a redução da proporção de esgoto sanitário (por exemplo, composição 90:10 e 100:0) pode ter resultado em menor eficiência de remoção de DQO devido ao efeito combinado de deficiência nutricional e potencial presença de compostos orgânicos tóxicos (por exemplo, xileno usado nas formulações de thinner) no efluente industrial. Em relação à toxidade por compostos inorgânicos, pode-se afirmar que os metais analisados estiveram presentes em concentrações inferiores àquelas supostamente tóxicas aos sistemas anaeróbios (SPEECE, 1996).

Em relação à DQO filtrada, calculada com base na DQO total afluente e na DQO filtrada efluente, percebe-se pela Figura 5 que a eficiência variou de 60 a 90\%, com valor máximo também obtido na fase VII. Em outras palavras, a proporção volumétrica ideal determinada experimentalmente em 70:30 (efluente da cabine de pintura:esgoto sanitário) permitiu adequada diluição dos compostos tóxicos presentes, fornecimento de quantidade suficiente de nutrientes e período adequado de adaptação da biomassa. É possível que a operação do reator UASB de bancada na relação 70:30 por um período maior tenha resultado em maiores eficiências de remoção de DQO, devido ao maior tempo de aclimatação ao compostos orgânicos tóxicos potencialmente presentes no efluente industrial.

As produções de lodo e biogás, embora não tenham sido quantificadas, foram visualmente pequenas. O lodo acumulado no reator, durante os 140 dias de operação, ocupou um volume correspondente à altura da terceira torneira, indicando que a produção de biomassa no sistema foi pequena, provavelmente em função dos problemas nutricionais e de toxicidade discutidos acima.

Decorridos 25 dias de funcionamento do reator anaeróbio com a adição de 100\% de água residuária industrial, percebeu-se que o $\mathrm{pH}$, que antes apresentava pouca variação, passou a sofrer constantes quedas, indicando instabilidade do processo e inibição microbiana. O reator anaeróbio continuou sendo operado nessa condição instável por cerca de mais um mês para avaliar a natureza da instabilidade e a efetividade de um sistema de pós- tratamento aeróbio na remoção complementar da DQO do efluente anaeróbio

A Figura 6 mostra que, durante o período de instabilidade, havia considerável acúmulo de AGV, principalmente acético e propiônico, no reator anaeróbio de fluxo ascendente. Durante tal período, a relação $\mathrm{DQO}_{\mathrm{AGV}} / \mathrm{DQO}_{\text {filtrada }}$ no efluente anaeróbio variou de 0,75 (26 dia ou

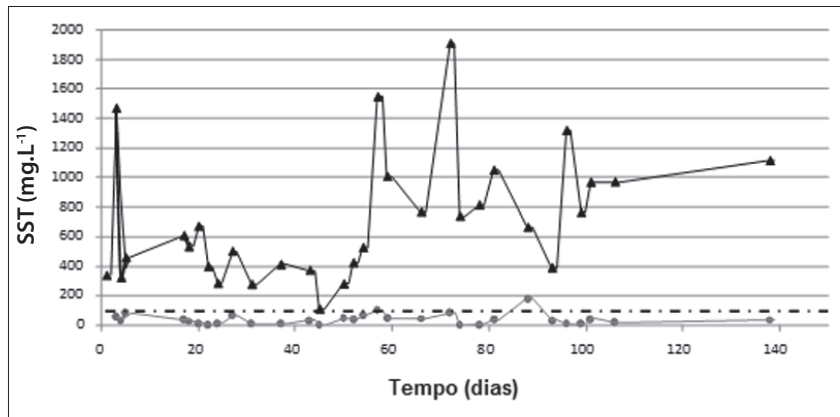

—SSTEfluente UASB —SST Afluente -. - SST Legislação (COPAM/CERH 01/2008)

SST: sólidos suspensos totais

Figura 3 - Variação temporal da concentração de sólidos afluente e efluente ao reator anaeróbio de fluxo ascendente.

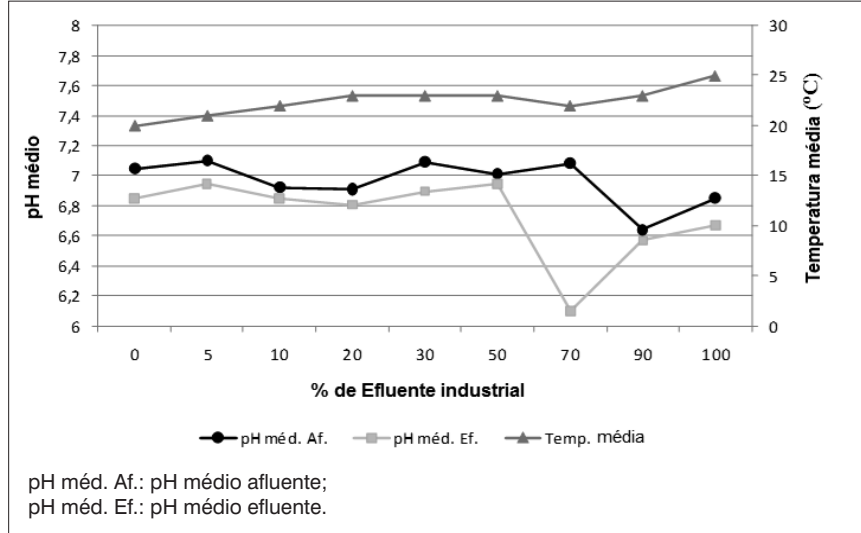

Figura 4 - Variação da temperatura e pH em função da proporção da água residuária industrial adicionada ao reator anaeróbio de fluxo ascendente

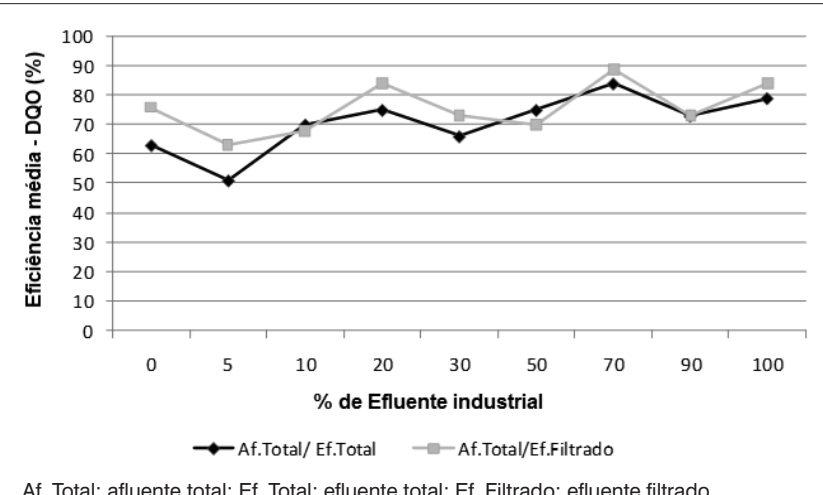

Af. Total: afluente total; Ef. Total: efluente total; Ef. Filtrado: efluente filtrado.

Figura 5 - Variação da eficiência de remoção de DQO (total e filtrada) em função da proporção de água residuária industrial no afluente do reator anaeróbio de fluxo ascendente 
início do distúrbio) a 0,52 (4 semana após o início do distúrbio), indicando que os micro-organismos anaeróbios estavam sendo inibidos por algum composto tóxico e/ou alguma deficiência nutricional.

Em função do estresse observado na fase IX, decidiu-se testar o uso de reator aeróbio como pós-tratamento do efluente produzido no reator UASB. Para investigar a tratabilidade do efluente industrial in natura (sem combinação com esgoto sanitário), decidiu-se manter a alimentação do reator UASB apenas com efluente industrial (composição de 100:0 usada na fase IX), sendo o efluente produzido nessa etapa encaminhado para o reator aeróbio, conforme detalhado a seguir.

\section{Ensaio de tratabilidade aeróbia}

A Tabela 4 apresenta os dados de monitoramento do reator UASB de bancada, bem como do reator aeróbio de mistura completa, que foi alimentado de forma semicontínua com o efluente anaeróbio. O reator aeróbio foi mantido a temperatura ambiente (19 a $23^{\circ} \mathrm{C}$ ) e a concentração de oxigênio dissolvido variou de 5,1 a $6,7 \mathrm{mg} \cdot \mathrm{L}^{-1}$. O teor de sólidos suspensos voláteis (SSV) no interior do reator aeróbio variou de 1.500 a $2.400 \mathrm{mg} . \mathrm{L}^{-1}$, o que resultou em relação A/M média de 0,03 mg DQO/mg SSV.dia. O baixo valor de A/M, característico de sistemas de aeração prolongados, foi em função do elevado tempo de detenção hidráulica (96 horas) adotado. $\mathrm{O}$ alto valor de TDH, o baixo valor de alimento/micro-organismo (A/M) e a ausência de recirculação de lodo caracterizam o sistema de pós-tratamento utilizado como sendo aquele empregado em lagoas aeradas.

Da Tabela 4 percebe-se que a eficiência global do tratamento combinado anaeróbio-aeróbio foi de, em média, 80\%, quando o sistema foi alimentado com $100 \%$ de efluente industrial. A Tabela 4 mostra que o pós-tratamento aeróbio (96 horas de detenção hidráulica) foi responsável pela remoção de, aproximadamente,

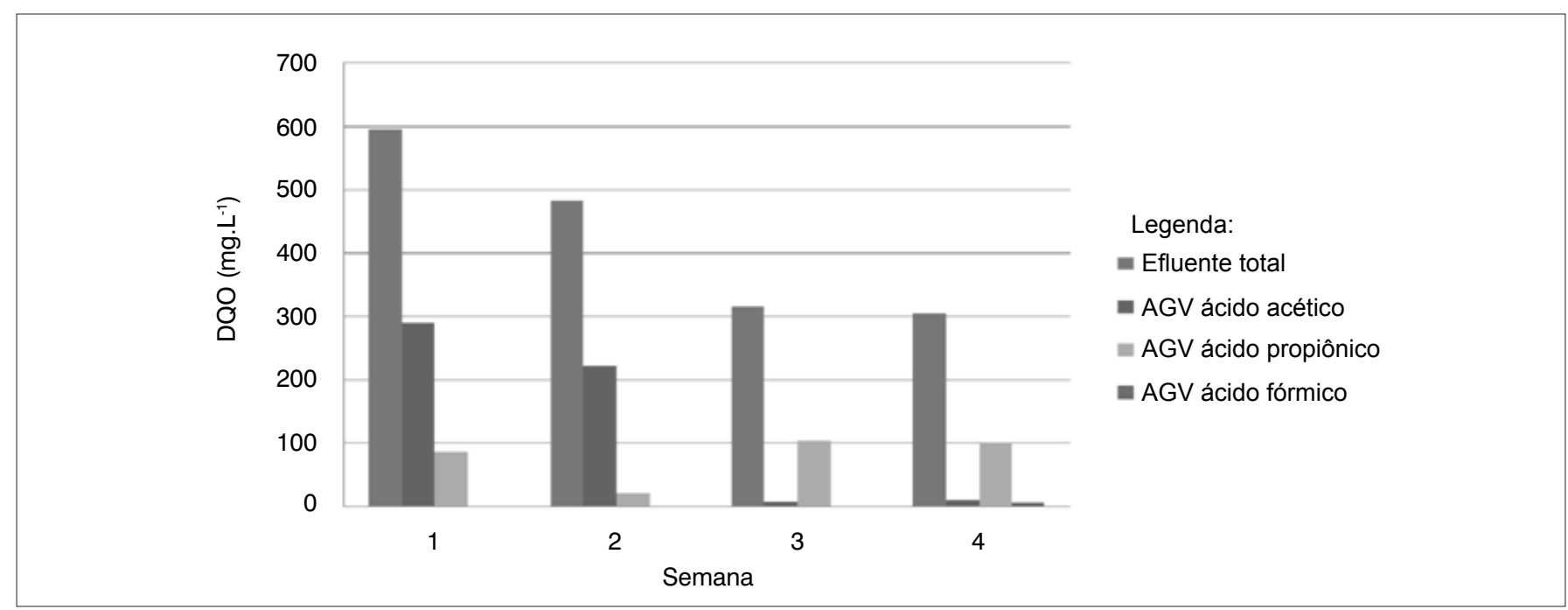

Figura 6 - Análises de ácidos graxos voláteis (AGV) de amostras coletadas no período de estresse do reator anaeróbio, ou seja, a partir do $25^{\circ}$ dia de operação da fase IX

Tabela 4 - Parâmetros analisados após o estresse do reator anaeróbio (a partir $25^{\circ}$ dia de operação da fase IX)

\begin{tabular}{|c|c|c|}
\hline Parâmetro & Parâmetro estatístico & Valor \\
\hline \multirow{3}{*}{$\mathrm{pH}$} & $\mathrm{n}$ & 28 \\
\hline & Média & 6,23 \\
\hline & Mínimo & 5,27 \\
\hline \multirow{3}{*}{ DQO afluente ao reator anaeróbio de fluxo ascendente $\left(\mathrm{mg}_{\mathrm{L}} \mathrm{L}^{-1}\right)$} & $\mathrm{n}$ & 16 \\
\hline & Média & 1498 \\
\hline & Mínimo & 901 \\
\hline \multirow{4}{*}{ DQO efluente ao reator anaeróbio de fluxo ascendente $\left(\mathrm{mg}_{\mathrm{L}} \mathrm{L}^{-1}\right)$} & $\mathrm{n}$ & 16 \\
\hline & Média & 660 \\
\hline & Mínimo & 348 \\
\hline & Máximo & 1330 \\
\hline \multirow{2}{*}{ DQO efluente ao reator aeróbio $\left(\mathrm{mg} \cdot \mathrm{L}^{-1}\right)$} & $\mathrm{n}$ & 15 \\
\hline & Média & 304 \\
\hline
\end{tabular}


$50 \%$ da DQO efluente do reator anaeróbio, que também apresentou eficiência média de remoção de apenas 50\%. Tais resultados reforçam a hipótese de toxicidade e/ou deficiência nutricional, tendo-se em vista que, a despeito dos elevados valores de detenção hidráulica na etapa aeróbia, a eficiência de remoção de DQO foi relativamente baixa.

Utilizando-se a DQO média efluente do reator anaeróbio (660 $\left.\mathrm{mg} / \mathrm{L}^{-1}\right)$ e considerando-se que não houve significativa remoção de $\mathrm{N}$ e P no reator anaeróbio, a relação DQO:N:P no afluente do reator aeróbio foi de, aproximadamente, 100:0,28:0,07. Como a relação ideal para o tratamento aeróbio é estabelecida em 100:5:1 (VON SPERLING, 1996), é provável que também tenha ocorrido deficiência de $\mathrm{N}$ e P nos ensaios de tratabilidade aeróbia, o que poderia explicar os baixos valores de remoção de DQO em detrimento do elevado valor de TDH utilizado. De qualquer forma, os resultados exploratórios realizados no reator aeróbio indicam que o uso do sistema combinado anaeróbio-aeróbio foi eficiente na remoção dos contaminantes causadores de DQO no efluente bruto produzido na cabine de pintura.

É provável que a combinação da água residuária da indústria moveleira com esgoto tipicamente sanitário na proporção de 70:30 e o seu tratamento em reator UASB, seguido de pós-tratamento aeróbio, resulte em eficiências de remoção ainda maiores. A vantagem da composição dos efluentes da cabine de pintura com o esgoto sanitário seria o fornecimento de nutrientes (por exemplo, $\mathrm{N}$ e P) deficientes na água residuária industrial e a diluição de eventuais compostos tóxicos presentes. Dessa forma, recomenda-se que outros trabalhos investiguem a combinação de reatores UASB com sistemas de lodos ativados para o tratamento de efluentes de indústrias moveleiras, estudando ainda o efeito de toxicidade de médio e longo prazo e avaliando a capacidade de adaptação da biomassa e estabilidade dos reatores biológicos na operação de longo prazo.

\section{Conclusões}

Os resultados de caracterização físico-química da água residuária de cabines de pintura de uma indústria moveleira indicaram elevado teor de matéria orgânica (DQO total de 634 a 2.790 mg.L.-1; DQO filtrada de 495 a $934 \mathrm{mg} . \mathrm{L}^{-1} ; \mathrm{DBO}_{5}$ total de 360 a $972 \mathrm{mg} . \mathrm{L}^{-1}$ e SSV de 428 a 876 mg. $L^{-1}$ ) e baixo teor de macronutrientes (NTK de 1,9 mg. $\mathrm{L}^{-1}$ e $\mathrm{P}_{\text {total }}$ de $0,5 \mathrm{mg} . \mathrm{L}^{-1}$, em valores médios), indicando que o tratamento biológico requer complementação nutricional. A maioria dos 21 elementos metálicos analisados esteve presente em baixas concentrações, sendo os maiores valores médios observados para metais de baixa toxicidade, tais como $\mathrm{Ca}\left(41,24 \mathrm{mg} . \mathrm{L}^{-1}\right)$, Fe $(5,52$ mg. $\left.\mathrm{L}^{-1}\right), \mathrm{Mg}\left(4,57 \mathrm{mg} \cdot \mathrm{L}^{-1}\right), \mathrm{Na}\left(4,97 \mathrm{mg} \cdot \mathrm{L}^{-1}\right)$ e $\mathrm{Zn}\left(0,77 \mathrm{mg} \cdot \mathrm{L}^{-1}\right)$. Os ensaios de tratabilidade da água residuária industrial em reator UASB de bancada (operado à temperatura ambiente e TDH de 10 horas) mostraram que uma eficiência máxima de remoção de 90\% foi obtida com a composição volumétrica de esgoto sanitário e água residuária industrial de 30:70. A alimentação do reator UASB somente com água residuária industrial mostrou, após 25 dias de operação, sinais de inibição microbiana com acúmulo de AGV e queda da eficiência de remoção de DQO para 44\%, ocasionada provavelmente pela deficiência nutricional. Contudo, o uso de um reator aeróbio de mistura completa (TDH de 48 horas), operado à temperatura ambiente e alimentado com o efluente do sistema de tratamento anaeróbio de fluxo ascendente, aumentou a eficiência global de remoção de DQO para $88 \%$, indicando que o uso de sistemas combinados anaeróbio-aeróbio podem ser uma opção tecnológica efetiva para o tratamento das águas residuárias das cabines de pintura de indústrias moveleiras.

\section{Referências}

ASSOCIAÇÃO BRASILEIRA DAS INDÚSTRIAS DO MOBILIÁRIO (ABIMÓVEL). Panorama do Setor Moveleiro. 2001 Disponível em < http://www.abimovel.org.br>. Acesso em 07/2008

ASSOCIAÇÃO BRASILEIRA DAS INDÚSTRIAS DO MOBILIÁRIO (ABIMÓVEL); SERVIÇO BRASILEIRO DE APOIO ÀS MICRO E PEQUENAS EMPRESAS (SEBRAE). Manual de Orientação ISO 14000 \& Produção Mais Limpa. Setor Moveleiro. Porto Alegre, 1998.

APHA, AWWA, WEF. Standard Methods for the Examination of Water and Wastewater. 20a edition. Washington, DC: APHA, AWWA, WEF, 1998

CORDI, L. et al. Montagem, partida e operação de um sistema de lodos ativados para o tratamento de efluentes: parâmetros físico-químicos e biológicos. Engenharia Ambiental: Pesquisa e Tecnologia, v. 5, n. 1, p. 97-115, 2008.
AQUINO, S.F. Formation of soluble microbial products (SMP) in anaerobic reactors during stress conditions. Thesis. Department of Chemical Engineering and Chemical Technology, Imperial College London, London, 2004.

BERTOLINO, S.M. Caracterização e tratabilidade dos esgotos produzidos pelo campus da Universidade Federal de Ouro Preto - MG. Dissertação (Mestrado em Engenharia Ambiental). Universidade Federal de Ouro Preto, Ouro Preto, MG, 2007.

CHERNICHARO, C.A.L. Princípios do tratamento biológico de águas residuárias: reatores anaeróbios. 2. ed. Belo Horizonte: UFMG, 2007.

CONSELHO ESTADUAL DE POLÍTICA AMBIENTAL (COPAM); CONSELHO ESTADUAL DE RECURSOS HÍDRICOS DE MINAS GERAIS (CERH-MG). Deliberação Normativa Conjunta COPAM/CERH-MG no 01 , 
de 05 de maio de 2008. Disponível em <http://www.siam.mg.gov.br/sla/ download.pdf?idNorma=8151>. Acesso em: 8 ago. 2008.

FERREIRA, A.L. Estudo dos efluentes gerados pelas indústrias moveleiras. Dissertação (Mestrado em Engenharia Ambiental). Universidade Federal de Ouro Preto, Ouro Preto, MG, 2003.

MESQUITA, P.L. Caracterização de produtos microbianos solúveis (SMPS) em reatores aeróbio e anaeróbio de bancada em diferentes condições operacionais. Dissertação (Mestrado em Engenharia Ambiental). Universidade Federal de Ouro Preto, Ouro Preto, MG, 2009.
SCHENEIDER, V.E. et al. Gerenciamento Ambiental na Indústria Moveleira - Estudo de caso no município de Bento Rodrigues. In: ENCONTRO NACIONAL DE ENGENHARIA DE PRODUÇÃO, 23, Ouro Preto, MG, 2003.

SPEECE, R.E. Anaerobic biotechnology for industrial wastewaters. Nashville, TN: Archae Press, 1996.

VON SPERLING, M. Introdução à qualidade das águas e ao tratamento de esgotos. 2. ed. - Belo Horizonte: Departamento de Engenharia Sanitária e Ambiental; Universidade Federal de Minas Gerais; 1996. 